\title{
Unmethylated MGMT Gene Promoter
}

National Cancer Institute

\section{Source}

National Cancer Institute. Unmethylated MGMT Gene Promoter. NCI Thesaurus. Code C132892.

A genetic finding indicating the absence of DNA methylation in the promoter region of the MGMT gene. This finding is associated with a poor prognosis in patients with glioblastoma. 